\title{
Gradient enriched linear-elastic crack tip stresses to estimate the static strength of cracked engineering ceramics
}

\author{
Harm Askes, Luca Susmel \\ Department of Civil and Structural Engineering, The University of Sheffield, Sheffield S1 3JD, United Kingdom
}

\begin{abstract}
According to Gradient Mechanics (GM), stress fields have to be determined by directly incorporating into the stress analysis a length scale which that takes into account the material microstructural features. This peculiar modus operandi results in stress fields in the vicinity of sharp cracks which are no longer singular, even though the assessed material is assumed to obey a linear-elastic constitutive law. Given both the geometry of the cracked component being assessed and the value of the material length scale, the magnitude of the corresponding gradient enriched linear-elastic crack tip stress is then finite and it can be calculated by taking full advantage of those computational methods specifically devised to numerically implement gradient elasticity. In the present investigation, it is first shown that GM's length scale can directly be estimated from the material ultimate tensile strength and the plane strain fracture toughness through the critical distance value calculated according to the Theory of Critical Distances. Next, by post-processing a large number of experimental results taken from the literature and generated by testing cracked ceramics, it is shown that gradient enriched linearelastic crack tip stresses can successfully be used to model the transition from the short- to the long-crack regime under Mode I static loading.
\end{abstract}

KEYwORDS. Length scale; Gradient elasticity; Theory of Critical Distances; Static breakage; Ceramics.

\section{INTRODUCTION}

$\mathrm{C}$ ertainly Linear Elastic Fracture Mechanics (LEFM) as formalised by Griffith, Irwin and others represents a ground-breaking point of no return in the field of fracture and strength of engineering materials, this holding true not only from a scientific, but also from an industrial point of view. What we have achieved in sectors such as, for instance, transportation and energy production would have been impossible without the LEFM based design theories. As to the accuracy and reliability of LEFM, in 1964 Irwin affirms [1]: “... linear elastic fracture mechanics already provides a rather complete set of mathematical tools. Additional experimental observations rather than additional methods of analysis are now the primary need for practical applications". Examination of the state of the art suggests that, as far as brittle failures are concerned, the international scientific community has taken the above statement literally: over the last five decades a big effort has been made mainly to experimentally extend the use of the LEFM concepts to different materials/loading conditions, rather than to develop new theoretical approaches, LEFM being treated as a kind of untouchable "religion". By challenging Irwin's belief, the present paper aims to show that gradient-enriched linear-elastic crack/notch tip stresses can directly be used to predict the detrimental effect of cracks on the overall static strength of engineering ceramics, the microstructural features of the assessed material being explicitly taken into account through the critical distance calculated according to the Theory of Critical Distances (TCD). This has the potential to represent an important step forward in the way cracked/notched components are designed against static loading. 


\section{FUNDAMENTALS OF GRADIENT ELASTICITY}

$\mathrm{B}$

ack in 1964, Mindlin published the first paper [2] addressing in a systematic way gradient enriched elasticity, where a novel continuum theory containing a number of additional constitutive parameters was proposed. Amongst the different attempts made so far to simplify the above approach by reducing the number of material parameters, certainly the model devised by Aifantis and co-workers [3-5] deserves to be mentioned explicitly. In more detail, such a model postulates that the enriched stress-strain relationship can be extended with the Laplacian of the strain as follows:

$$
\sigma=\mathrm{C}\left(\varepsilon-\ell^{2} \nabla^{2} \varepsilon\right)
$$

where $\sigma$ and $\varepsilon$ are the stresses and strains, respectively, $\mathrm{C}$ is a fourth-order tensor containing the elastic moduli, and $\ell$ is a length scale parameter that represents the underlying microstructure. The most interesting feature of the above formulation of gradient elasticity is that it can efficiently be implemented numerically and then used, according to the procedure summarised below, to address problems of practical interest [6-8]. In particular, initially the following standard equation has to be solved:

$$
\mathrm{K} \underline{\mathrm{u}}=\underline{\mathrm{f}}
$$

where $\mathrm{K}$ is the conventional linear elastic stiffness matrix, $\underline{u}$ is the vector containing the nodal displacements, and, finally, $\underline{\mathrm{f}}$ is the vector summarising the externally applied nodal forces. Once the displacements are obtained from Eq. (2), they can be used to determine the gradient-enriched nodal stresses $\underline{\sigma}$ from

$$
\int_{\Omega}\left(\mathrm{N}^{\mathrm{T}} \mathrm{SN}+\sum_{\xi} \frac{\partial \mathrm{N}^{\mathrm{T}}}{\partial \xi} \mathrm{S} \ell^{2} \frac{\partial \mathrm{N}}{\partial \xi}\right) \mathrm{d} \Omega \underline{\sigma}=\int_{\Omega} \mathrm{N}^{\mathrm{T}} \mathrm{B} \mathrm{d} \Omega \underline{\mathrm{u}}
$$

In the above relation, $\mathrm{N}$ is the matrix summarising the shape functions used to interpolate the stresses, $\mathrm{B}$ is the matrix containing the derivatives of the displacement shape functions, and, finally, $\mathrm{S}$ is the elastic compliance matrix.

To conclude, it is worth recalling here that the most important implication of directly incorporating material length scale $\ell$ into the stress analysis is that, even in the presence of cracks and sharp notches, the resulting stress fields are not singular in spite of the fact that the material being designed is forced to obey a linear-elastic constitutive law [9].

\section{THEORY OF CRITICAL DistanCES AND STATIC ASSESSMENT}

$\mathrm{I}$ $\mathrm{n}$ the presence of cracks subjected to Mode I static loading, the TCD postulates that fast fracture takes place when a critical distance based effective stress, $\sigma_{\text {eff, }}$ exceeds the material inherent strength, $\sigma_{0}$ [10], i.e.:

$$
\sigma_{\text {eff }} \leq \sigma_{0} \Leftrightarrow \text { non-propagation of the crack }
$$

Further, as far as the static assessment is concerned, independently from the ductility level of the material being design, the stress analysis can directly be performed by adopting a simple linear-elastic constitutive law [11-13], provided that the material inherent strength $\sigma_{0}$ is determined consistently [10-13]. The appropriate way of experimentally determining $\sigma_{0}$ will be reviewed below briefly. The above considerations should make it evident that designing cracked materials against static loading according to the TCD implies performing a bi-parametrical post-processing of the linear-elastic stress fields acting on the material in the vicinity of the crack tips, the critical distance and the inherent material strength being the two adopted design parameters.

When specifically dealing with static failures, the TCD's critical distance is recommended to be determined from:

$$
\mathrm{L}=\frac{1}{\pi}\left(\frac{\mathrm{K}_{\mathrm{Ic}}}{\sigma_{0}}\right)^{2}
$$

where $\mathrm{K}_{\mathrm{Ic}}$ is the LEFM plane strain fracture toughness. The TCD's effective stress, $\sigma_{\text {eff, }}$ can then be calculated according to either the Point Method, the Line Method, or the Area Method as follows [1, 14]: 


$$
\begin{array}{ll}
\sigma_{\text {eff }}=\sigma_{\mathrm{y}}\left(\theta=0, \mathrm{r}=\frac{\mathrm{L}}{2}\right) & \text { Point Method (PM) } \\
\sigma_{\text {eff }}=\frac{1}{2 \mathrm{~L}} \int_{0}^{2 \mathrm{~L}} \sigma_{\mathrm{y}}(\theta=0, \mathrm{r}) \mathrm{dr} & \text { Line Method (LM) } \\
\sigma_{\text {eff }}=\frac{4}{\pi \mathrm{L}^{2}} \int_{0}^{\pi / 2} \int_{0}^{\mathrm{L}} \sigma_{\mathrm{y}}(\theta, \mathrm{r}) \mathrm{drd} \theta & \text { Area Method (AM) }
\end{array}
$$

The adopted symbols as well as the meaning of the effective stress determined according to definitions (6), (7), and (8) are explained in Fig. 1.

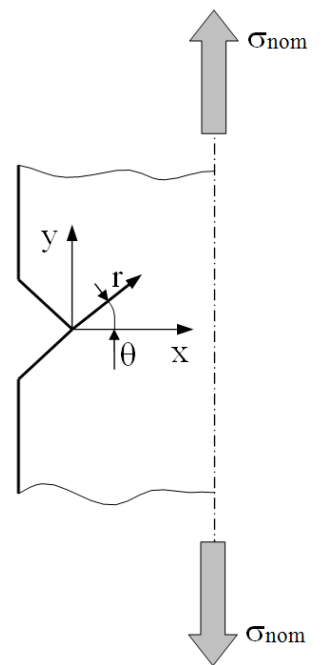

(a)

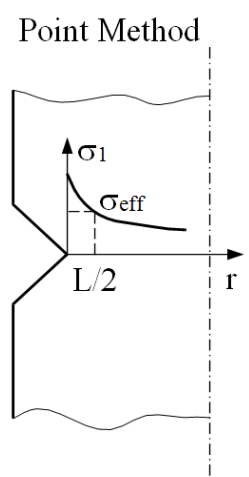

(b)

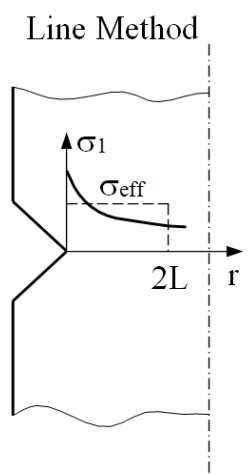

(c)

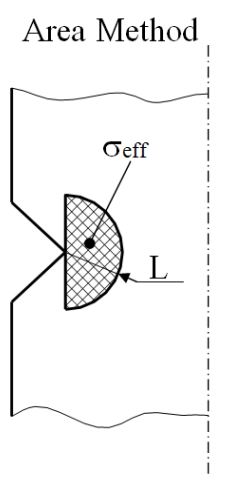

(d)

Figure 1: Definition of the local systems of coordinates (a) and effective stress, $\sigma_{\text {eff }}$, calculated according to the Point Method (b), Line Method (c), and Area Method (d).

Eq. (4) to (8) clearly show that inherent material strength $\sigma_{0}$ plays a role of primary importance when the TCD is used to design cracked components against static loading. Brittle materials are experimentally seen to have an inherent material strength which is always very close to the material ultimate tensile strength, $\sigma_{U T S}$ [14-16]. On the contrary, when the fast fracture process zone is characterised by large scale plastic deformations, in general, $\sigma_{0}$ reaches a value which is somewhat larger than the plain material UTS $[10,11,13]$. Another important aspect which is worth highlighting here is that $\sigma_{0}$ adopts a value higher than $\sigma_{U T S}$ also in those situations in which the breakage of the plain parent material occurs by different mechanisms (such as, for instance, by the propagation of pre-existing microstructural defects) [10]. The considerations reported above clearly suggest that the only way to accurately determine $\sigma_{0}$ is by testing notched specimens containing stress risers whose presence results in different stress distributions in the vicinity of the tested geometrical features [10-13].

To conclude, when the TCD is used to specifically design cracked engineering ceramics against static loading, the inherent material strength is seen to be equal to the material ultimate tensile strength [15]. This greatly simplifies the problem. According to this remark, in what fallows GM will be used to model the sensitivity of engineering ceramics loaded in Mode I to both short- and long-cracks by taking $\sigma_{0}$ invariably equal to $\sigma_{U}$ ts.

\section{LINKING THE LENGTH SCALES OF GM AND THE TCD}

$\mathrm{B}$

y using the Area Method argument re-interpreted according to non-local mechanics, in two recent investigations $[17,18]$ we have proven that the length scale parameter, $\ell$, employed by GM to perform the stress analysis, Eq. (1), can directly be related to critical distance L, Eq. (5). Since the reasoning resulting in the $\ell$ vs. L relationship has 
already been explained in great detail elsewhere $[17,18]$, in what follows just its fundamental steps are summarised briefly. In order to coherently link $\ell$ to L, according to Neuber's structural volume concept [19], the initial hypothesis is formed that the process zone defining the overall strength of the investigated cracked material is circular in bi-dimensional situations and spherical in tri-dimensional bodies, its radius being equal to L [20]. Given a generic material point having coordinates $(\mathrm{X}, \mathrm{Y})$, nonlocal stresses $\sigma^{\text {nl }}$ at this point can directly be derived from the local stresses $\sigma$ determined at those points having coordinates $(\mathrm{X}+\mathrm{x}, \mathrm{Y}+\mathrm{y})$ that are in the vicinity of the point at which the non-local stresses themselves are evaluated, i.e.:

$$
\sigma^{\mathrm{nl}}(\mathrm{X}, \mathrm{Y})=\frac{1}{\pi \mathrm{L}^{2}} \int_{-\infty}^{\infty} \int_{-\infty}^{\infty} \mathrm{H}\left(\mathrm{L}^{2}-\mathrm{x}^{2}-\mathrm{y}^{2}\right) \sigma(\mathrm{X}+\mathrm{x}, \mathrm{Y}+\mathrm{y}) \mathrm{dy} \mathrm{dx}
$$

In the above equation $\mathrm{H}$ is the Heaviside function where $\mathrm{H}(\mathrm{s})=1$ when $\mathrm{s}>0$ and $\mathrm{H}(\mathrm{s})=0$ otherwise, $\mathrm{s}$ being a generic variable. Observing that factor $\pi \mathrm{L}^{2}$ is used for normalisation reasons, the local stresses expanded in a Taylor series at the material point having coordinates $(\mathrm{X}, \mathrm{Y})$ take on the following value:

$$
\sigma^{\mathrm{nl}}=\frac{1}{\pi \mathrm{L}^{2}} \int_{-\infty}^{\infty} \int_{-\infty}^{\infty} \mathrm{H}\left(\mathrm{L}^{2}-\mathrm{x}^{2}-\mathrm{y}^{2}\right)\left(\sigma+\mathrm{x} \frac{\partial \sigma}{\partial \mathrm{x}}+\mathrm{y} \frac{\partial \sigma}{\partial \mathrm{y}}+\ldots\right) \mathrm{dy} \mathrm{dx}
$$

By so doing, the stresses and their derivatives are evaluated at point $(\mathrm{X}, \mathrm{Y})$ and, therefore, they can be taken out of the integral. If the terms in the integral are rewritten according to polar coordinates $\theta$ and $r$, where $x=r \cdot \cos \theta$ and $y=r \cdot \sin \theta$, the right-hand side of Eq. (10) can be elaborated. For instance, the second derivative terms is found to be:

$$
\frac{1}{\pi \mathrm{L}^{2}} \int_{-\infty}^{\infty} \int_{-\infty}^{\infty} \mathrm{H}\left(\mathrm{L}^{2}-\mathrm{x}^{2}-\mathrm{y}^{2}\right) \frac{1}{2} \mathrm{x}^{2} \frac{\partial^{2} \sigma}{\partial \mathrm{x}^{2}} \mathrm{dy} \mathrm{dx}=\frac{1}{\pi \mathrm{L}^{2}} \frac{\partial^{2} \sigma}{\partial \mathrm{x}^{2}} \int_{0}^{2 \pi} \int_{0}^{\mathrm{L}} \frac{1}{2} \mathrm{r}^{2} \cos \theta \cdot \mathrm{rdr} \mathrm{d} \theta=\frac{1}{8} \mathrm{~L}^{2} \frac{\partial^{2} \sigma}{\partial \mathrm{x}^{2}}
$$

According to Eq. (11), it easy to observe that all terms with odd powers of $\mathrm{x}$ or y cancel. After some straightforward algebra, one obtains:

$$
\sigma^{\mathrm{nl}}=\sigma+\frac{1}{8} \mathrm{~L}^{2} \nabla^{2} \sigma+\ldots
$$

Finally, by using the explicit-to-implicit transition as formalised by Peerlings et al. [20], Eq. (12) can be rearranged as follows:

$$
\sigma^{\mathrm{nl}}-\frac{1}{8} \mathrm{~L}^{2} \nabla^{2} \sigma^{\mathrm{nl}}=\sigma+\ldots
$$

Eq. (9), which is the starting point of the reasoning summarised above, represents a link between the AM [10] and gradient elasticity as formalised by Aifantis and co-workers [3-5], so that, if the terms of order L 4 and higher are ignored, the the $\ell$ vs. L relationship can explicitly be written as:

$$
\ell^{2} \approx \frac{1}{8} \mathrm{~L}^{2} \Leftrightarrow \mathrm{L} \approx 2 \sqrt{2} \ell
$$

\section{GRADIENT ENRICHED TIP STRESSES TO ESTIMATE STATIC STRENGTH OF CRACKED CERAMICS}

$\mathrm{I}$ $\mathrm{n}$ order to check the accuracy of gradient enriched tip stresses in estimating the static strength of cracked engineering ceramics under Mode I static loading a number of experimental results were selected from the technical literature, the mechanical properties of the investigated materials being summarised in Tab 1. Such results were generated by testing cracked samples having different geometries which include: controlled surface flaws, surface scratches, large pores, and sharp notches. The selected experimental results are summarised in the normalised Kitagawa-Takashi diagram plotting the ratio between the nominal gross stress resulting in static breakage, $\sigma_{\text {th }}$, and the material ultimate tensile strength, $\sigma_{U T S}$, against a normalised equivalent length calculated as $\mathrm{F}^{2} \mathrm{a} / \mathrm{L}$, where $\mathrm{F}$ is the LEFM shape factor and a the crack length. The main advantage of the above schematisation is that experimental results generated by testing samples having shape factor different from unity can directly be compared to the case of a central crack in an infinite plate loaded in tension (for which $\mathrm{F}$ is invariably equal to 1$)$. 


\begin{tabular}{ccccc}
\hline Material & Ref. & $\begin{array}{c}\boldsymbol{\sigma}_{\text {UTs }} \\
{[\mathrm{MPa}]}\end{array}$ & $\begin{array}{c}\mathbf{K}_{\mathbf{I c}} \\
{\left[\mathrm{MPa} \cdot \mathrm{m}^{1 / 2}\right]}\end{array}$ & $\begin{array}{c}\mathbf{L} \\
{[\mathrm{mm}]}\end{array}$ \\
$\mathrm{SiC}$ & {$[21]$} & 620 & 3.7 & 0.011 \\
$\mathrm{Si}_{3} \mathrm{~N}_{4}$ & {$[21]$} & 650 & 4.5 & 0.015 \\
$\mathrm{Al}_{2} \mathrm{O}_{3}$ & {$[21]$} & 200 & 3.1 & 0.076 \\
$\mathrm{Sialon}$ & {$[21]$} & 920 & 4.6 & 0.008 \\
$\mathrm{Si}_{3} \mathrm{~N}_{4}$ & {$[22]$} & 1160 & 7.8 & 0.014 \\
$\mathrm{Al}_{2} \mathrm{O}_{3}$ & {$[22]$} & 290 & 4.5 & 0.077 \\
$\mathrm{Si}_{3} \mathrm{~N}_{4}$ & {$[23]$} & 920 & 5.6 & 0.012 \\
$\mathrm{Si}_{3} \mathrm{~N}_{4}$ & {$[24]$} & 915 & 5.0 & 0.010 \\
$\mathrm{Si}_{3} \mathrm{~N}_{4}$ & {$[25,26]$} & 880 & 5.0 & 0.010 \\
$\mathrm{Si}_{3} \mathrm{~N}_{4}$ & {$[27]$} & 700 & 5.0 & 0.016 \\
$\mathrm{Si}_{3} \mathrm{~N}_{4}$ & {$[28]$} & 700 & 5.0 & 0.016 \\
$\mathrm{Si}_{3} \mathrm{~N}_{4}$ & {$[29]$} & 510 & 5.0 & 0.031 \\
$\mathrm{Si}_{3} \mathrm{~N}_{4}$ & {$[26]$} & 340 & 5.0 & 0.069 \\
$\mathrm{Al}_{2} \mathrm{O}_{3}$ & {$[25]$} & 790 & 3.5 & 0.006 \\
$\mathrm{Al}_{2} \mathrm{O}_{3}$ & {$[25]$} & 610 & 3.5 & 0.010 \\
$\mathrm{Al}_{2} \mathrm{O}_{3}$ & {$[30]$} & 610 & 3.5 & 0.010 \\
$\mathrm{Al}_{2} \mathrm{O}_{3}$ & {$[30]$} & 390 & 3.5 & 0.026 \\
$\mathrm{Al}_{2} \mathrm{O}_{3}$ & {$[31]$} & 390 & 3.5 & 0.026 \\
$\mathrm{Al}_{2} \mathrm{O}_{3}$ & {$[28]$} & 210 & 3.5 & 0.088 \\
\hline
\end{tabular}

Table 1: Mechanical properties of the investigated engineering ceramics.

The curve plotted in the chart of Fig. 2 summarises the predictions made through the gradient enriched crack tip stresses calculated according to GM, the $\ell$ vs. L relationship being the one given by Eq. (14). Such estimates were obtained by solving GM FE models simulating a bi-dimensional rectangular plate with a central through-thickness crack and subjected to tensile loading. The considered gross widths ranged in the interval $0.25 \mathrm{~mm}-64 \mathrm{~mm}$. The ratio between the semi-crack length, a, and the gross width was set constant and equal to 0.05 . This resulted for the modelled cracked samples in a shape factor, F, invariably equal to unity. Finally, the boundary conditions of the gradient-enrichment step were taken as zero Neumann conditions throughout.

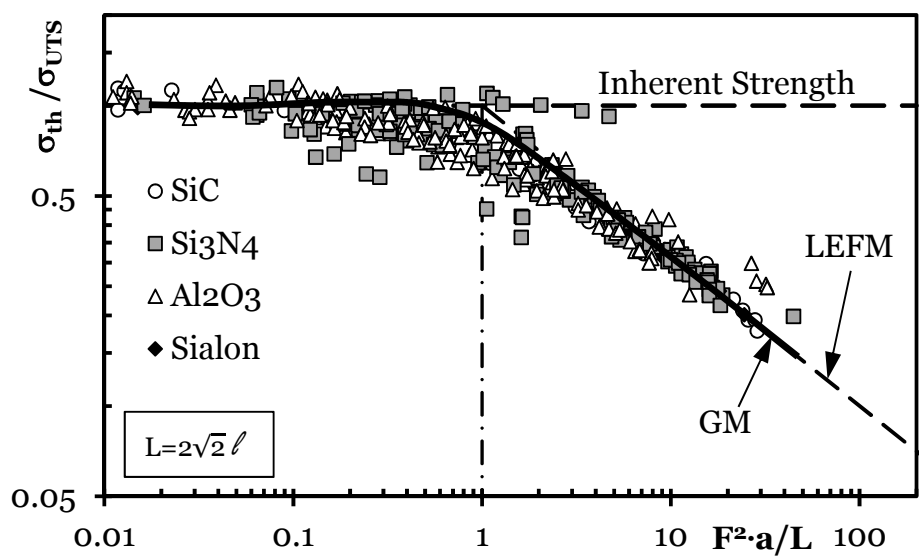

Figure 2: Accuracy of gradient enriched tip stresses in estimating the transition from the short- to the long-crack regime under Mode I static loading, the mechanical properties of the considered engineering ceramics being summarised in Tab 1 .

The chart of Fig. 2 clearly suggests that, as far as engineering ceramics are concerned, gradient-enriched crack tip stresses are successful in modelling the transition from the short- to the long-crack regime. In particular, the above diagram makes it evident that GM is capable of matching the inherent material strength in the very short-crack region by correctly modelling, at the same time, the long-crack behaviour as well. 


\section{CONCLUSIONS}

he validation exercise summarised in the present paper strongly supports the idea that gradient-enriched crack tip stresses can successfully be used to perform the static assessment of cracked components. The GM based design methodology proposed and validated in the present paper by post-processing a large number of experimental results generated by testing engineering ceramics has the potential to turn into an important step forward in developing alternative methods to model the detrimental effect of cracks and defects in engineering components and structures. In particular, since, according to GM's modus operandi, gradient enriched stresses can directly be calculated at any material points (crack tips included), components containing both cracks and defects could directly be designed against static loading by following the same strategy as the one commonly adopted to perform, as suggested by continuum mechanics, the fatigue assessment of un-cracked bodies.

\section{REFERENCES}

[1] Irwin, G.R., Structural aspects of brittle fracture, Applied Materials Research, 3 (1964) 65-81.

[2] Mindlin, R.D., Micro-structure in linear elasticity, Arch. Rat. Mech. Analysis, 16 (1964) 52-78.

[3] Aifantis, E.C., On the role of gradients in the localization of deformation and fracture, Int. J. Engng. Sci., 30 (1992) 1279-1299.

[4] Altan, S.B., Aifantis, E.C., On the structure of the mode III crack-tip in gradient elasticity, Scripta Metall. Mater., 26 (1992) 319-324.

[5] Ru, C.Q., Aifantis, E.C., A simple approach to solve boundary-value problems in gradient elasticity, Acta Mech., 101 (1993) 59-68.

[6] Askes, H., Gutiérrez, M.A., Implicit gradient elasticity, Int. J. Numer. Meth. Engng., 67 (2006) 400-416.

[7] Askes, H., Morata I., Aifantis E.C., Finite element analysis with staggered gradient elasticity, Comput. Struct., 86 (2008) 1266-1279.

[8] Askes, H., Gitman, I.M., Non-Singular Stresses in Gradient Elasticity at Bi-Material Interface with Transverse Crack, Int. J. Fract., 156 (2009) 217-222.

[9] Askes, H., Aifantis, E.C., Gradient elasticity in statics and dynamics: An overview of formulations, length scale identification procedures, finite element implementations and new results, Int. J. Solids Struct., 48 (2011) 1962-1990.

[10] Taylor, D., The Theory of Critical Distances: A new perspective in fracture mechanics, Elsevier, Oxford, UK (2007).

[11] Susmel, L., Taylor, D., On the use of the Theory of Critical Distances to predict static failures in ductile metallic materials containing different geometrical features, Engng. Fract. Mech., 75 (2008) 4410-4421.

[12] Susmel, L., Taylor, D., The Theory of Critical Distances to estimate the static strength of notched samples of Al6082 loaded in combined tension and torsion. Part I: Material cracking behaviour, Engng. Fract. Mech., 77 (2010) $452-469$.

[13] Susmel L., Taylor D., The Theory of Critical Distances to estimate the static strength of notched samples of Al6082 loaded in combined tension and torsion. Part II: Multiaxial static assessment, Engng. Fract. Mech., 77 (2010) $470-$ 478.

[14] Whitney, J.M., Nuismer, R.J., Stress fracture criteria for laminated composites containing stress concentrations, J. Composite Mater., 8 (1974) 253-265.

[15] Taylor, D., Predicting the fracture strength of ceramic materials using the theory of critical distances, Engng. Fract. Mech., 71 (2004) 2407-2416.

[16] Susmel, L., Taylor, D., The theory of critical distances to predict static strength of notched brittle components subjected to mixed-mode loading, Eng Frac Mech, 75 3-4 (2008) 534-550.

[17] Susmel, L., Askes, H., Material length scales in fracture analysis: from Gradient Elasticity to the Theory of Critical Distances, Computational Technology Reviews, 6 (2012) 63-80.

[18] Susmel, L., Askes, H., Bennett, T., Taylor, D., Theory of Critical Distances vs. Gradient Mechanics in modelling the transition from the short- to long-crack regime at the fatigue limit, Fatigue Fract. Engng. Mater. Struct., (2013) - in press.

[19] Neuber, H., Theory of Notch Stresses. Springer, Berlin, (1958).

[20] Peerlings, R.H.J., de Borst, R., Brekelmans, W.A.M., de Vree, J.H.V., Gradient enhanced damage for quasi-brittle materials, Int. J. Numer. Meth. Engng., 39 (1996) 3391-3403. 
[21] Kimoto, H., Usami, S., Miyata, H. Relationship between strength and flaw size in glass and polycrystalline ceramics. Japan Soc. Mech. Engng., 51 (1985) 2482-2488.

[22] Anw, K., Kim, B.A., Iwasa, M., Ogura, N., Process zone size failure criterion and probabilistic fracture assessment curves for ceramics, Fatigue fract. Engng mater. Struct., 15 (2) (1992) 139-149.

[23] Taniguchi, Y., Kitazumi, J., Yamada, T., Bending stress analysis of ceramics based on the statistical theory of stress and fracture location, J. Jap. Soc. Mater. Sci., 38 (1988) 777-782.

[24] Nagase, Y., Hoshide, T., Furuya, H., Yamada, T., Room and high temperature strengths for ring specimen of sintered silicon nitride, In: 33rd Ann. Meeting. Society of Materials Science, Japan, (1984) 150-152.

[25] Kirchner, H. P., Gruver, R. M., Sotter, W. A., Characteristics of flaws at fracture origins and fracture stressflaw size relations in various ceramics, Mater. Sci. Eng., 22 (1976) 147-156.

[26] Bourne, W.C., Tressler, R.E., Alteration of flaw sizes and $\mathrm{K}_{\mathrm{Ic}}$ of $\mathrm{Si}_{3} \mathrm{~N}_{4}$ ceramics by molten salt exposure, In: Int. Symp. Frac. .Mech. Ceram., Plenum, New York 3 (1978) 113-124.

[27] Kawai, M., Abe, H., Nakayama, J., The effect of surface roughness on the strength of silicon nitride, In: Proc. Int. Symp. Factors Densification Sinter. Oxide Nonoxide Ceram., Tokyo, (1978) 545-556.

[28] Kimoto, H., Usami, S., Miyata, H., Flaw size dependence in fracture stress of glass and polycrystalline ceramics, Japan Soc. Mech. Eng., 841-852 (1984) 34-40.

[29] Takahashi, I., Usami, S., Nakakado, K., Miyata, H., Shida, S., Effect of defect size and notch root radius on fracture strength of engineering ceramics, J. Ceram. Soc. Japan, 93 (1985) 186-194.

[30] Katayama, Y., Matsuo, Y., Relationship between strength and defect size in alumina, In: 3rd Symp. High Temp. Mater., Ceramic Soc. of Japan, (1984) 34-38.

[31] Iseki, T., Maruyama, T., Hanafusa, K., Suzuki, H., Effect of surface roughness on the bending strength of graphite and alumina at high temperatures, J. Ceram. Soc. Japan, 86 (1978) 547-552. 